\title{
Self-inflicted eye injuries: a review
}

N Patton

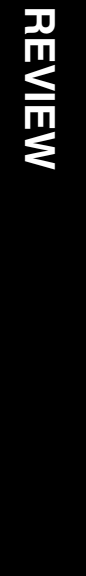

\begin{abstract}
Purpose To review the pathogenesis, clinical characteristics, and management of selfinflicted eye injuries.

Methods Review of the medical literature. Results Psychiatric theories of pathogenesis for self-inflicted behaviour include religious and sexual ideation, symbolism, guilt, and displacement. Biological theories include disorders of serotonergic, dopaminergic, and opiate neurotransmitters. Clinical characteristics of self-mutilators include acute or chronic psychoses, drug-induced psychoses, other psychiatric conditions, and certain organic states. The majority are young-to-early middle-aged male subjects, though it can also rarely occur in children. Management of selfinflicted eye injury requires close cooperation between ophthalmologists and psychiatrists as well as other medical specialists, to ensure quick resuscitation of the patient, prompt diagnosis and treatment of any injuries, and treatment of the underlying behaviour that led to the injuries.

Conclusions Self-inflicted eye injuries are a rare but important group of ophthalmic conditions that require close cooperation between different medical specialties to ensure optimum care of the often severely disturbed patient.

Eye (2004) 18, 867-872. doi:10.1038/sj.eye.6701365

Published online 5 March 2004
\end{abstract}

Keywords: self-inflicted; ocular injury; selfmutilation; autoenucleation; oedipism; review

\section{Introduction}

Self-inflicted eye injuries are an unusual, but important, form of self-mutilation. ${ }^{1}$ They have been associated with a variety of disorders, including paranoid schizophrenia, ${ }^{2-5}$ druginduced psychosis, ${ }^{3,6,7}$ obsessive-compulsive disorder, $3,8,9$ depression, $3,10,11$ mental retardation, ${ }^{12}$ and ritualistic behaviour. ${ }^{1}$ It has also been reported in patients with a variety of organic illnesses, including neurosyphilis, ${ }^{13}$ Lesch-Nyhan syndrome, ${ }^{12}$ and structural brain lesions. ${ }^{14}$ It has been described in both adults and children, but occurs most commonly in young adults with acute or chronic psychoses. ${ }^{3,15}$ Most of the literature features individual case reports. This review summarises the literature of deliberate selfinflicted eye injuries, including the pathogenesis, both psychiatric and biological, clinical characteristics, and management.

\section{History and mythology}

Self-inflicted eye injuries play a prominent role in our culture and ancient literature. The eye has been described as the gateway to the soul, and Athens was known as the eye of ancient Greece. The eye can act as a symbol of protection from evil as well as representing evil, reflecting malicious thoughts.

Sacrificing an eye has been associated in ancient mythology with the gain of other rewards. According to ancient Nordic mythology, the Norse god Odin sacrificed one of his eyes in order to drink from the Spring of Mimir, whose waters contained wisdom and knowledge. $^{16}$

Ancient Egyptian mythology has the legend of Horus, whose eyes were cast out in a battle, only to be returned to him and, as a result, he became stronger and more able to resist evil forces. $^{17}$

Most famous of all is the story of Oedipus, the legendary king of Thebes. He unwittingly killed his father and married his mother. After pestilence had descended on Thebes, he consulted an oracle, who informed him of his murder and incest and that this was the cause for the pestilence. As a result, Oedipus gouged out his own eyes using his mother's brooch.

Christian hagiography also contains many references to self-inflicted eye injury as a means of obtaining higher redemption. The King James Version of the bible states, 'If thy right eye offends thee, pluck it out and cast it from thee: for it is profitable for thee that one of thy
Department of

Ophthalmology

Princess Alexandra Eye

Pavilion Edinburgh, UK

Correspondence:

N Patton

Department of

Opthalmology

Princess Alexandra Eye

Pavilion

Chalmers Street

Edinburgh EH3 9HA, UK

Tel: + 441315554886

Fax: +441315361000

E-mail: niallpatton@

hotmail.com

Received: 8 August 2003 Accepted: 10 October 2003 Published online: 5 March 2004 
members should perish, and not that thy whole body should be cast into hell' (Matthew 5:29). Ophthalmology has three patron saints, all of whom used self-blinding as a punishment for sinful thoughts. ${ }^{18}$ Saint Lucia of Syracuse tore out her eyes in remorse for looking lustfully at a man who wished to marry her, and sacrificed them to God, who gave her new eyes as a reward for her sacrifice. St Triduana attracted the attention of a prince who demanded 'the most excellent beauty of thine eyes', to which she proceeded to offer them to him, having plucked them out. To this day, the waters of St Triduana's well in Edinburgh are believed by some to have tremendous healing powers, particularly for eye complaints. Pious St Medana is believed to have left Ireland for Scotland to flee the attentions of a determined suitor, only to have her pursuant follow her. In desperation, she tore out her eyes and offered them to him, which was effective in discouraging him from further pursuit; when she later washed her face in a stream nearby, her eyesight returned.

\section{Psychiatric theories}

Self-mutilation is defined as physical injury inflicted by an individual to various parts of their body, either as a single event or as repeated episodes, without any conscious intent for suicide. Favazza and Rosenthal ${ }^{19}$ classified self-mutilation into major, stereotypical, and superficial subtypes. Forms of superficial self-mutilation commonly encountered include chewing fingers, biting lips, pulling hair (including eyelashes), and burning skin. Stereotypical self-mutilation frequently occurs as repetitive fixed behaviour, commonly in institutionalised retards. ${ }^{20,21}$ The major self-mutilation includes wristslashing, head banging, and autocastration, as well as self-enucleation (oedipism).

Numerous psychodynamic theories exist to explain self-inflicted eye injuries as a form of self-mutilation. Altered body image is commonly present among selfmutilators, and there is an almost universal association with either religious or sexual ideation.

\section{Religious ideation}

Approximately half of all cases of self-inflicted eye injury have psychotic preoccupations with sinfulness and higher deities. ${ }^{22,23}$ This often results in the displacement of these preoccupations towards the eye, which has become a symbol both of the physical and spiritual outside world. When the psychoses are no longer contained, the organ that provoked the impulses (the eye) becomes the focus of a punitive response (eye injury) by the patient, in order to serve as a defence against either observing or performing a forbidden act.

\section{Sexual ideation}

It has been reported that around one-third of cases with self-inflicted eye injury have sexual ideation. Some theories suggest the eye as a symbol of the penis, and that injury may represent some form of symbolic selfcastration. ${ }^{2}$ It has also been described as an acting out of oedipal conflicts of sexuality, as a sign of repressed homosexual impulses, and as an autoerotic practise, analogous to masturbation. ${ }^{15}$

Both religious and sexual ideations may often coexist, and the eyes may act as a symbol of the self onto which conflicts, fears, and guilt ${ }^{15,20}$ (either religious or sexual) are displaced, and thus by elimination or mutilation of the eye, relief from these feelings is obtained. Thus, selfmutilation of the eye allows one to destroy the 'devilish responsible self and yet live'. ${ }^{5}$

In patients with borderline personalities, selfmutilation has been suggested as a response to a lack of a significant 'other', on whom the patient depends, and that the self-mutilation confirms a sense of reality to the patient. $^{11}$

Whatever the cause, successful self-mutilation of the eye may often be followed by anxiety relief, $, 11,20,24$ whereas frustration is common and repeated attempts can be made, when unsuccessful.

\section{Biochemical theories}

Disorders of neurotransmitters have been implicated in some forms of self-mutilation, ${ }^{2}$ in particular the serotonergic function. An increased serotonergic action within the striatum has been suggested as being crucial in the appearance of self-injurious behaviour in LeschNyhan syndrome, ${ }^{12}$ and selective serotonin reuptake blockers have been shown to be effective in controlling self-injurious behaviour in both Prader-Willi syndrome and Lesch-Nyhan syndrome. ${ }^{2}$ Abnormalities of serotonin metabolism have also been described in Gilles de la Tourette syndrome, which frequently has selfmutilation as a feature. ${ }^{25}$ Apter $e t a^{26}$ postulated that serotonin abnormalities may be related to impulsivity, anxiety, and aggression. Dysfunction of opiate neurotransmission as well as dopaminergic dysfunction ${ }^{25}$ have also been implicated in self-injurious behaviour. It has been suggested that self-mutilators may have a higher pain threshold. ${ }^{12,27}$

\section{Clinical characteristics of ocular self-mutilators}

The majority of self-inflicting eye injuries occurs in young to early middle-aged males. ${ }^{11}$ Most suffer from acute or chronic psychoses with chronic schizophrenia being the commonest association. Self-inflicted eye injuries commonly occur during episodes of visual or 
auditory hallucinations. They frequently cite 'evil' committed by the eye, prior to attempted self-mutilation.

Drug- or alcohol-induced acute psychoses are well described in association with self-inflicted eye injuries. ${ }^{7,28}$ Drugs particularly implicated include psychotomimetics, such as phencyclidine (PCP) ${ }^{29}$ and lysergic acid diethylamide (LSD). ${ }^{6}$ It has also been described with abuse of cocaine, ${ }^{30}$ cannabis and amphetamines. ${ }^{7}$ Substance abuse often occurs in conjunction with chronic schizophrenia.

Other psychiatric conditions described in association with self-inflicted eye injuries include obsessivecompulsive disorder, ${ }^{3,8,9}$ profound affective disorder (particularly psychotic depression), ${ }^{11}$ post-traumatic stress disorder, ${ }^{30}$ Munchausen syndrome, ${ }^{31-33}$ and borderline personality disorder. ${ }^{34}$

Organic states described in association with selfinflicting eye injuries include temporal lobe epilepsy, ${ }^{35}$ encephalitis $^{36}$ neurosyphilis, ${ }^{13}$ frontal lobe encephalomalacia, ${ }^{14}$ and there has been one report in association with diabetes. ${ }^{37}$

Other groups who are reported to have an increased risk of self-inflicting eye injury include institutionalised groups, ${ }^{21}$ such as prisoners, ${ }^{2,11,30}$ and those living alone, unwed, or unemployed. ${ }^{30}$

While the majority of cases of self-inflicted eye injuries occur in adults, it rarely can also occur in the pediatric group, ${ }^{12,38,39}$ particularly in association with mental retardation syndromes such as Lesch-Nyhan ${ }^{12,39}$ and Gilles de la Tourette. ${ }^{25,40}$ Lesch-Nyhan syndrome is an $\mathrm{X}$-linked condition characterised by choreo-athetoid movements, severe mental retardation, and self-mutilation. The biochemical defect is the absence of hypoxanthine-guanine phosphoribosyltransferase and hyperuricaemia. Gilles de la Tourette syndrome is characterised by motor and behavioural abnormalities. Purine and dopaminergic metabolic abnormalities have been implicated.

Self-inflicting eye injuries have also been described in association with autism, ${ }^{39}$ where head-banging is a frequent association. In any child with self-inflicted eye injury, physical, or emotional abuse should be considered. $^{39}$

\section{Forms of self-inflicted eye injury}

Ocular self-mutilation can occur in many different forms, from dramatic self-enucleation (Oedipism) to mild anterior segment trauma. All components of the eye and orbit may be involved.

\section{Self-enucleation (oedipism)}

Self-enucleation is by far the most dramatic of self-inflicted eye injuries. It was first described by
Bergman in 1846, and Blonel in 1906 was the first to propose the term 'oedipism'.$^{10}$ Manual enucleation must be performed with sudden and sufficient force to avulse the optic nerve, although it has been performed experimentally in less than $1 \mathrm{~min}$ in a cadaveric eye. ${ }^{41}$ Use of the fingers is the commonest mechanism whereby it is attempted, though the use of other instruments, including sharp scissors ${ }^{4}$ and knives, have been reported. ${ }^{42,43}$ The fingers of the hand may be advanced along the medial wall of the orbit, gaining access to the retro-orbital space, and then a levering action causing the optic nerve to avulse, along with torn extraocular muscles ${ }^{44}$ and blood vessels. The attempt is usually unilateral, but bilateral attempts are well documented in the literature. ${ }^{4,22,44,45}$ Enucleation will be accompanied by severance of the ophthalmic artery, and therefore significant bleeding will ensue. This bleeding will be orbital if it occurs anterior to the optic foramen, ${ }^{4}$ but posterior severance of the ophthalmic artery has been reported to cause subarachnoid haemorrhage. ${ }^{10}$ There is one report of a patient developing an aneurysm at the juncture of the internal carotid artery and the ophthalmic artery, after having self-enucleated the ipsilateral eye. ${ }^{20}$

As self-enucleation requires such force, unsuccessful self-enucleation may cause disruption of the globe's integrity via scleral rupture, predisposing to panophthalmitis. Unsuccessful self-enucleation may also lead to visual failure due to penetrating injury, orbital compression due to haemorrhage or oedema, or retinal contusions.

Further risk from optic nerve avulsion includes damage to the optic chiasm, resulting in contralateral temporal hemianopia. ${ }^{44,46}$ Suppurative meningitis has been documented as a result of self-enucleation. ${ }^{47}$

\section{Management}

Anyone who has successfully or unsuccessfully attempted self-enucleation is deeply disturbed, and requires immediate hospital admission. Self-inflicted enucleation may often be accompanied by significant blood loss, and immediate resuscitation of the patient is imperative. Urgent psychiatric and ophthalmic assessments are necessary.

Urgent ophthalmic evaluation is necessary in any successful or unsuccessful attempt at self-enucleation as there may be a need for prompt surgical repair. The nature of the surgical repair will depend on the clinical findings, and extensive posterior segment repair may frequently be necessary. In the event of the eye being irretrievably damaged beyond repair, prompt surgical removal may be necessary to reduce the risk of sympathetic ophthalmia. 
It may not be clear from examination whether the patient has irreversible blindness as a result of their injuries. Investigations, including neuroimaging ${ }^{4,10}$ and electro-diagnostic test may be of help. ${ }^{10}$ In the presence of severe orbital compression, due to either haematoma or oedema, high-dose systemic steroids may be of benefit, ${ }^{4,44}$ although their role in exacerbating any psychoses must be borne in mind. Prophylactic antibiotics are used as routine in any attempted selfenucleation.

Intense scrutiny of the fellow eye as well as the eye suffering the injury is necessary, as a small number of patients will have attempted bilateral self-inflicted eye injury, and the clinical findings may not always be obvious. Furthermore, the patient may be unlikely to proffer a history of inflicting injury to the other eye.

As well as a close ophthalmic examination, a comprehensive neurological examination is mandatory, in particular to recognise any signs of meningism, suggestive of subarachnoid haemorrhage. At some stage, formal visual field testing is needed to exclude any optic chiasmal injury. ${ }^{10,44}$

Psychiatric evaluation allows for diagnostic evaluation, understanding of the drives and psychoses that have driven the patient to such extreme actions, and the instigation of immediate treatment. This treatment may take the form of neuroleptic medication, antidepressants, and above all close observation, to ensure there are no further episodes of any selfdestructive behaviour. If present, detoxification of any substance abuse may be necessary. Occasionally, electroconvulsive therapy has been used to good effect. In addition, patients as well as family members will require help in coming to terms with the extreme religious and/or sexual delusions that led to the attempted self-enucleation. All patients will require longterm follow-up of their condition. There is some evidence to suggest that selective serotonin uptake blockers may help influence future self-mutilatory behaviour.

Hospital admission needs to be continued until the patient's mental state is stabilised and their ophthalmic condition has been addressed. The role of orbital prosthesis in the rehabilitation of these patients has been reported as successful in some cases. ${ }^{7}$

\section{Orbital injuries}

Injuries to the orbit are a rare form of self-mutilation. ${ }^{3,48-50}$ However, they are of great importance, as failure to recognise the injury may be fatal. A penetrating object of greater than $5 \mathrm{~cm}$ in length may reach the cranial cavity via the superior orbital fissure, shearing vessels, and nerves as it travels. In one extraordinary case, ${ }^{51}$ this was performed using a ballpoint pen, and it had been pushed through with such force that it had reached the occipital region, and the blunt end of the pen was not protruding from the orbit. Through the patient informing the medical staff that this was an old injury, there was a delay in prompt intervention, and the injury proved fatal within 4 days. Orbital injuries tend to affect the right eye more than the left eye, due to hand dominance and the avoidance head turn. The direction of the object's path may give a clue as to whether the act was deliberate or an accident. Deliberate self-inflicted injuries tend to occur in a backward fashion, towards the posterior fossa, whereas accidental injuries tend to have a more upward direction, toward the frontal lobe. ${ }^{51}$ Pens $^{3,49,51}$ and pencils ${ }^{50}$ are the commonest reported objects causing self-inflicted orbital injuries, while there has been one report of using a toothbrush. ${ }^{48}$ Frequently, the eye is spared significant injury due to scleral resistance. ${ }^{51}$ Rarely, firearms may be the mode of the self-inflicted injury, often resulting in severe injury of both ocular and orbital tissues. ${ }^{52}$

Prompt diagnosis and appropriate treatment of orbital injuries may lead to only minor sequelae. As with all selfinflicted eye injuries, the case history from the patient must be treated with a degree of suspicion, as they may attempt to withhold information from the clinician. These patients may be in need of prompt resuscitation, due to bleeding both externally as well as intracranially. If an intraorbital foreign object is suspected, urgent neuroimaging is mandatory to determine exact location and depth of the object. ${ }^{51,53,54}$ Urgent neurosurgical intervention may be required.

\section{Injury to the ocular surface and anterior segment}

Both mechanical ${ }^{2,55}$ and chemical assaults ${ }^{2,11,31}$ on the ocular surface can range from the trivial to the severe resulting in irreversible ocular surface changes, such as corneal infections and opacification, ${ }^{31,56}$ cicatricial changes $^{2}$ and blindness. Mechanical scratching and beating of the ocular surfaces causes subconjunctival haemorrhages and abrasions, but in severe cases the blunt trauma (particularly in the case of head banging) can also cause retinal and vitreal haemorrhages as well as retinal detachment. ${ }^{39}$ Lens dislocation has also been reported due to self-inflicted blunt trauma. ${ }^{57}$

While these injuries occur in patients with deliberate self-mutilating intention, they can also often be factitious, representing an intention of the patient either to gain emotional and/or financial gain (malingering). ${ }^{58}$

Common modes of mechanical trauma include the use of fingernails to induce both corneal and linear surface abrasions, ${ }^{2}$ which can often mimic herpetic infections. Mechanical rubbing of the eyes can also mimic conjunctivitis, recurrent corneal erosions, and scleritis. ${ }^{58}$ Often admission and close scrutiny of the patients' 
behaviour is required before diagnosis is possible. Exploration into the patients' motives may help in resolving the behaviour.

Trichotillomania is defined as the irresistible urge to pull one's own hair, and can often involve the eyelashes and eyebrows. ${ }^{59,60}$ Treatment involves a combination of pharmacological and behavioural therapy.

\section{Posterior segment injuries}

As stated earlier, any attempted enucleation that is unsuccessful must be examined for any evidence of posterior segment trauma, as prompt surgical intervention may be necessary due to scleral laceration or perforation, ${ }^{57}$ retinal tears (including giant retinal tears) ${ }^{12}$ and retinal detachments. ${ }^{2,12,39}$

Furthermore, significant anterior ocular surface blunt trauma (form eye-rubbing/eye-beating/ head-banging) can produce significant posterior segment trauma, including vitreal and retinal haemorrhages and even retinal detachment. ${ }^{2,9}$ These types of injuries frequently occur in severely disturbed children.

There are rare reports of self-inflicted intraocular injections into the eye, including substances such as mercury in a schizophrenic patient. ${ }^{61}$ Bacillus cereus endophthalmitis has been reported in a drug abuser who was injecting drugs into his eye. ${ }^{62}$

Other posterior segment injuries reported include solar retinopathy due to deliberate sun gazing. ${ }^{63-65}$

\section{Conclusion}

Self-inflicted eye injuries are a rare, but an important group of eye conditions that can present great management problems in a difficult group of patients. Treatment of the presenting ophthalmic problem must be combined with due consideration of the underlying cause, whether biological or psychiatric. Close cooperation between ophthalmologists and psychiatrists, as well as physicians, neurologists, and neurosurgeons when necessary will ensure optimum care for these often severely disturbed patients.

\section{References}

1 Favazza AR. The coming of age of self-mutilation. J Nerv Ment Dis 1998; 186(5): 259-268.

2 Yang HK, Brown GC, Magargal LE. Self-inflicted ocular mutilation. Am J Ophthalmol 1981; 91(5): 658-663.

3 Tapper CM, Bland RC, Danyluk L. Self-inflicted eye injuries and self-inflicted blindness. J Nerv Ment Dis 1979; 167(5): 311-314.
4 Stannard K, Leonard T, Holder G, Shilling J. Oedipism reviewed: a case of bilateral ocular self-mutilation. $\mathrm{Br} J$ Ophthalmol 1984; 68(4): 276-280.

5 Rogers T. Self-inflicted eye-injuries. Br J Psychiatry 1987; 151: 691-693.

6 Rosen DH, Hoffman AM. Focal suicide: self-enucleation by two young psychotic individuals. Am J Psychiatry 1972; 128(8): 1009-1012.

7 Bergua A, Sperling W, Kuchle M. Self-enucleation in drugrelated psychosis. Ophthalmologica 2002; 216(4): 269-271.

8 Oren DA, Laor N. Self-inflicted eye injury. Am J Psychiatry 1987; 144(2): 248-249.

9 Stinnett JL, Hollender MH. Compulsive self-mutilation. J Nerv Ment Dis 1970; 150(5): 371-375.

10 Khan JA, Buescher L, Ide CH, Pettigrove B. Medical management of self-enucleation. Arch Ophthalmol 1985; 103(3): 386-389.

11 Kennedy BL, Feldmann TB. Self-inflicted eye injuries: case presentations and a literature review. Hosp Community Psychiatry 1994; 45(5): 470-474.

12 Ashkenazi I, Shahar E, Brand N, Barton E, Blumenthal M. Self-inflicted ocular mutilation in the pediatric age group. Acta Paediatr 1992; 81(8): 649-651.

13 Winchel RM, Stanley M. Self-injurious behavior: a review of the behavior and biology of self-mutilation. Am J Psychiatry 1991; 148(3): 306-317.

14 Waldfogel S, Field HL, Wu L. Oedipism in a patient with frontal lobe encephalomalacia. Brain Injury 1994; 8(4): 377-381.

15 MacLean G, Robertson BM. Self-enucleation and psychosis. Report of two cases and discussion. Arch Gen Psychiatry 1976; 33(2): 242-249.

16 Grapplin P. Germanic lands: the mortal gods. In: Grimal P (ed). Larousse World Mythology. Hamlyn Publishing: London, 1965.

17 Davison HRE. Gods and Myths of Northern Europe. Penguin: New York, 1964.

18 Duke-Elder S. Systems of Ophthalmology, Vol 7. Kimpton: London, 1962, pp 470-471.

19 Favazza AR, Rosenthal RJ. Diagnostic issues in selfmutilation. Hosp Community Psychiatry 1993; 44(2): 134-140.

20 Eisenhauer GL. Self-inflicted ocular removal by two psychiatric inpatients. Hosp Community Psychiatry 1985; 36(2): 189-191.

21 Shore D, Anderson DJ, Cutler NR. Prediction of selfmutilation in hospitalized schizophrenics. Am J Psychiatry 1978; 135(11): 1406-1407.

22 Aksaray G, Erol S, Kaptanoglu C. Self-inflicted bilateral eye injury by a schizophrenic patient. Gen Hosp Psychiatry 2000; 22(3): 215-216.

23 Ananth J, Kaplan HS, Lin KM. Self-inflicted enucleation of an eye: two case reports. Can J Psychiatry 1984; 29(2): 145-146.

24 Crowder JE, Gross CA, Heiser JF, Crowder AM. Self-mutilation of the eye. J Clin Psychiatry 1979; 40(10): 420-423.

25 Robertson MM, Trimble MR, Lees AJ. Self-injurious behaviour and the Gilles de la Tourette syndrome: a clinical study and review of the literature. Psychol Med 1989; 19(3): 611-625.

26 Apter A, van Praag HM, Plutchik R, Sevy S, Korn M, Brown SL. Interrelationships among anxiety, aggression, impulsivity, and mood: a serotonergically linked cluster? Psychiatry Res 1990; 32(2): 191-199. 
27 Garcia-Estrada A. Self-inflicted eye injuries. Br J Psychiatry 1988; 153: 266

28 Shiwach RS. Autoenucleation - a culture-specific phenomenon: a case series and review. Compr Psychiatry 1998; 39(5): 318-322.

29 Moskovitz RA, Byrd T. Rescuing the angel within: PCPrelated self-enucleation. Psychosomatics 1983; 24(4): 402-403, 40,6 .

30 Leslie J, Taff ML, Patel I, Sternberg A, Fernando MM. Selfinflicted ocular injuries. A rare form of self-mutilation. Am J Forensic Med Pathol 1984; 5(1): 83-88.

31 Voutilainen R, Tuppurainen K. Ocular Munchhausen syndrome induced by incest. Acta Ophthalmol (Copenh) 1989; 67(3): 319-321.

32 Rosenberg PN, Krohel GB, Webb RM, Hepler RS. Ocular Munchausen's syndrome. Ophthalmology 1986; 93(8): $1120-1123$.

33 Winans JM, House LR, Robinson HE. Self-induced orbital emphysema as a presenting sign of Munchausen's syndrome. Laryngoscope 1983; 93(9): 1209-1211.

34 Goldsmith W. Self-enucleation: further views. Am J Psychiatry 1973; 130(3): 329.

35 Soebo J. Automutilatio bulborum. A rare case of selfmutilation in an epileptic. Acta Ophthalmologica 1948; 26: 451-453.

36 Goodhart SP, Savitsky N. Self-mutilation in chronic encephalitis. Avulsion of both eyeballs and extraction of teeth. Am J Med Sci 1933; 185: 674-684

37 Brown BZ. Self-inflicted injuries of the eye. Ann Ophthalmol 1972; 4(2): 147-149, (passim).

38 Niiranen M, Raivio I. Eye injuries in children. $\mathrm{Br}$ J Ophthalmol 1981; 65(6): 436-438.

39 Noel LP, Clarke WN. Self-inflicted ocular injuries in children. Am J Ophthalmol 1982; 94(5): 630-633.

40 Van Woert MH, Yip LC, Balis ME. Purine phosphoribosyltransferase in gilles de la Tourette syndrome. N Engl J Med 1977; 296(4): 210-212.

41 Axenfeld T. Uber Luxation, Zerstorung und Herausreissung des Augapfels als Selbstverstummelung bei Geisteskranken. $\mathrm{Z}$ Augenheilkd 1899; 1: 128.

42 Field HL, Waldfogel S. Severe ocular self-injury. Gen Hosp Psychiatry 1995; 17(3): 224-227.

43 Jones NP. Self-enucleation and psychosis. $\mathrm{Br} J$ Ophthalmol 1990; 74(9): 571-573.

44 Krauss HR, Yee RD, Foos RY. Autoenucleation. Surv Ophthalmol 1984; 29(3): 179-187.

45 Yucel B, Ozkan S. A rare case of self-mutilation: selfenucleation of both eyes. Gen Hosp Psychiatry 1995; 17(4): 310-311.
46 Distler JA, Utrata PJ, File MP. Traumatic enucleation: a clinicopathologic case report. Ann Ophthalmol 1981; 13(10): 1169-1170.

47 Nettleship E. Intracranial affections: on a case of meningitis after excision of the eye ball. Trans Ophthalmol Soc UK 1886; 6: $445-480$.

48 Lasky JB, Epley KD, Karesh JW. Household objects as a cause of self-inflicted orbital apex syndrome. J Trauma 1997; 42(3): 555-558.

49 Bowen DI. Self-inflicted orbitocranial injury with a plastic ballpoint pen. Br J Ophthalmol 1971; 55(6): 427-430.

50 Albert DM, Burns WP, Scheie HG. Severe orbitocranial foreign-body injury. Am J Ophthalmol 1965; 60(6): 1109-1111.

51 Lunetta P, Ohberg A, Sajantila A. Suicide by intracerebellar ballpoint pen. Am J Forensic Med Pathol 2002; 23(4): 334-337.

52 Shuttleworth GN, Galloway PH. Ocular air-gun injury: 19 cases. J Roy Soc Med 2001; 94(8): 396-399.

53 Kirkby GR. Penetrating orbitocranial injury with a snooker cue. Br Med J (Clin Res Ed) 1986; 293(6562): 1646.

54 Sharif S, Roberts G, Phillips J. Transnasal penetrating brain injury with a ball-pen. Br J Neurosurg 2000; 14(2): 159-160.

55 Palmowski A, Heinz G, Ruprecht KW. Self-inflicted injuries of the eye: differential diagnosis of self-inflicted lacerating corneal injury. Klin Monatsbl Augenheilkd 1994; 204(1): 30-32.

56 Chern KC, Meisler DM, Wilhelmus KR, Jones DB, Stern GA, Lowder CY. Corneal anesthetic abuse and Candida keratitis. Ophthalmology 1996; 103(1): 37-40.

57 Brown R, al-Bachari MA, Kambhampati KK. Self-inflicted eye injuries. Br J Ophthalmol 1991; 75(8): 496-498.

58 Zamir E, Read RW, Rao NA. Self-inflicted anterior scleritis. Ophthalmology 2001; 108(1): 192-195.

59 Mawn LA, Jordan DR. Trichotillomania. Ophthalmology 1997; 104(12): 2175-2178.

60 Smith JR. Trichotillomania: ophthalmic presentation. Aust NZ J Ophthalmol 1995; 23(1): 59-61.

61 Jornod P, Vannotti M, Dascal DR, Auer C, Berode M Savolainen H. Voluntary mercury poisoning: biological consequences and psychiatric significance. Schweiz Rundsch Med Prax 1997; 86(22): 946-951.

62 Blackmon DM, Calvert HM, Henry PM, Westfall CT. Bacillus cereus endophthalmitis secondary to self-inflicted periocular injection. Arch Ophthalmol 2000; 118(11): 1585-1586.

63 Favazza AR. Literature on sun gazing. Am J Psychiatry 1991; 148(2): 281-282.

64 Anaclerio AM, Wicker HS. Self-induced solar retinopathy by patients in a psychiatric hospital. Am J Ophthalmol 1970; 69(5): 731-736.

65 Eigner EH. Self-induced solar retinitis. Am J Ophthalmol 1966; 61(6): 1546-1547. 